\title{
COMUNICAÇÃO
}

\section{PROPAGAÇÃO DE ESTACAS APICAIS DE FIGUEIRA: DIFERENTES AMBIENTES, ÁCIDO INDOLBUTÍRICO E TIPO DE ESTACA}

\author{
Propagation of fig tree apical cuttings: Different ambient, indolbutyric acid and type of cutting \\ Rafael Pio ${ }^{1}$, José Darlan Ramos², Nilton Nagib Jorge Chalfun², Tiago Chaltein Almeida Gontijo, \\ Vander Mendonça ${ }^{4}$, Edney Paulo Carrijo ${ }^{3}$,Edvan Alves Chagas ${ }^{1}$
}

\begin{abstract}
RESUMO
Objetivou-se com o presente trabalho verificar a influência de diferentes ambientes, da gema apical e do ácido indolbutírico no enraizamento de estacas apicais de figueira. Foram coletadas estacas lenhosas apicais de figueira em agosto, padronizadas com $20 \mathrm{~cm}$ de comprimento e sem folhas. Os tratamentos constituíram-se de estacas com ou sem a gema apical, imersas ou não em solução de AIB a $2000 \mathrm{mg} . \mathrm{L}^{-1}$ por 10 segundos e dois diferentes ambientes de propagação (casa-de-vegetação, com temperatura em torno de $27 \pm 2{ }^{\circ} \mathrm{C}$ e 85\% UR; telado, constituído por sombrite a 50\% de luminosidade e regas manuais diárias). As estacas foram acondicionadas em recipientes plásticos $\left(10 \times 20 \mathrm{~cm}\right.$, capacidade de $\left.650 \mathrm{~cm}^{3}\right)$, preenchido com substrato terra e areia 2:1 v/v. Após 60 dias foram avaliados a porcentagem de estacas enraizadas e brotadas, número de folhas, brotos, raízes emitidas da estaca e comprimento médio das brotações. Concluiu-se que a casa-de-vegetação representa o ambiente ideal de propagação para estacas apicais de figueira; deve ser mantida a gema apical nas estacas; não há necessidade da utilização de AIB.
\end{abstract}

Termos para indexação: Ficus carica L., estaquia e enraizamento.

\begin{abstract}
The aim of work was to verify the influence of different ambient, apical bud and indolbutyric acid in the rooting of fig tree apical cutting. Woody cutting of fig tree apical was collected in August, standardized with $20 \mathrm{~cm}$ of length and without leaves. The treatments were constituted of cutting with or without the apical bud, immerged or not in solution of IBA at $2000 \mathrm{mg} . \mathrm{L}^{-1}$ for 10 seconds and two different propagation ambient (green house, with temperature around $27 \pm 2{ }^{\circ} \mathrm{C}$ and $85 \%$ UR; telado, constituted by sombrite at $50 \%$ of brightness). The cuttings were conditioned in bag plastic $\left(10 \mathrm{x} 20 \mathrm{~cm}\right.$, capacity of $\left.650 \mathrm{~cm}^{3}\right)$, filled with substrate soil and sand 2:1 v/v. After 60 days, rooting and sprouting percentage, number of leaves, sprouts and roots emitted the cutting and sprouts lengths were evaluated. It was ended that the green house represents the propagation ambient ideal for fig tree apical cutting; the apical bud should be maintained in the cutting; there is not need use of IBA.
\end{abstract}

Index terms: Ficus carica L., cutting and rooting.

(Recebido para publicação em 24 de junho de 2004 e aprovado em 10 de janeiro de 2006)

A cultura da figueira (Ficus carica L.) vem apresentando expansão mundial devido as suas peculiaridades de rusticidade e adaptabilidade às mais diversas condições climáticas; é cultivada no Brasil principalmente nas regiões Sul e Sudeste, devido às condições climáticas de invernos suaves e verões quentes ou relativamente suaves e úmidos (CHALFUN et al., 1997). No Brasil, a cultivar Roxo de Valinhos constitui-se praticamente a única cultivar utilizada comercialmente, caracterizada pelo seu elevado vigor e produtividade (PENTEADO, 1999). No Estado de São Paulo, a figueira é uma importante frutífera cultivada, com cerca de 840 mil pés em cultivo, com uma produção média nas últimas cinco safras de 9685 toneladas, sendo que na região de Valinhos concentra-se mais de $80 \%$ da produção paulista de figo (IEA, 2002). Já no Estado de Minas Gerais, toda a produção mineira está voltada à obtenção de figos verdes para a indústria (COELHO et al., 2002).

Comercialmente, a propagação da figueira através de estacas lisas tem sido o processo mais utilizado no Brasil, embora possam ser utilizados outros métodos de propagação (SILVA, 1983), aproveitando o material oriundo

'Engenheiro Agrônomo, Dr., Pesquisador Científico Centro APTA Frutas/IAC - Av. Luiz Pereira dos Santos, n¹500 - 13.214-820 - Corrupira Jundiaí,SP - rafaelpio@iac.sp.gov.br; echagas@iac.sp.gov.br

Engenheiro Agrônomo, Dr., Professor de Fruticultura - Departamento de Agricultura/DAG - Universidade Federal de Lavras /UFLA - Cx. P. 3037 37.200-000 - Lavras, MG - darlan@ufla.br nchalfun@ufla.br

${ }^{3}$ Graduando do curso de Agronomia, Bolsista de Iniciação Científica-CNPq - Universidade Federal de Lavras/ UFLA - Cx. P. 3037 - $37.200-000$ Lavras,MG - tiagocgontijo@hotmail.com; edneycarrijo@ufla.br

${ }^{4}$ Engenheiro Agrônomo, Dr., Professor de Fruticultura - Universidade Estadual de Mato Grosso do Sul/UEMS - Cassilândia, MS - vanderm@uems.br 
da poda hibernal (julho-setembro). Em vista da grande importância desta cultura, observa-se que existem várias técnicas de manejo que precisam ser melhoradas, como, por exemplo, o plantio das estacas diretamente na cova, visto que esta prática vem acarretando elevado custo de implantação devido ao baixo índice de enraizamento das estacas, por não haver coincidência da estaquia com o período chuvoso, principalmente na região Sudeste, originando desuniformidade do pomar e, muitas vezes, necessidade de replantio (ANTUNES et al., 1996; GONÇALVES, 2002). Outro método de propagação da figueira é o enraizamento prévio das estacas em viveiros, sendo esta, uma forma alternativa e promissora na propagação da figueira, podendo utilizar estacas de menor comprimento, facilitando assim o manejo das mudas no viveiro, além de propiciar a seleção de plantas de qualidade e plantio no período chuvoso, possibilitando a obtenção de um pomar uniforme e vigoroso (CHALFUN \& HOFFMANN, 1997; PIO, 2002).

O enraizamento de estacas é influenciado por substâncias hormonais presentes nas mesmas. As auxinas são as responsáveis pelo enraizamento, dentre elas destacando-se o AIA (ácido indolacético), que está presentes nas regiões de crescimento - ápice caulinar, gemas de crescimento e folhas (HINOJOSA, 2000). Assim, a presença da gema apical pode influenciar o processo de enraizamento das estacas de figueira, influenciando ainda na melhoria da qualidade do sistema radicular formado e parte aérea.

Segundo Alvarenga (1990), entre as principais funções biológicas das auxinas, pode-se citar o crescimento de órgãos, especialmente as raízes. Outra forma de favorecer o balanceamento endógeno de auxina é o fornecimento exógeno de auxinas sintéticas (fitoreguladores). O fitoregulador mais utilizado no enraizamento de estacas é o ácido indolbutírico (AIB), por se tratar de uma substância fotoestável, de ação localizada e menos sensível à degradação biológica, em comparação as demais auxinas sintéticas (FACHINELLO et al., 1995; HOFFMANN et al., 1996). Segundo Hartmann et al. (2002), é de extrema importância a utilização correta das concentrações de fitoreguladores a serem aplicados na base das estacas, sendo que a concentração ideal varia com a espécie em que se está trabalhando. No caso de estacas apicais de figueira, foi verificado que a concentração de $2000 \mathrm{mg} . \mathrm{L}^{-1}$ de AIB promoveu melhores resultados no enraizamento (PIO et al., 2004).
Outro ponto importante no enraizamento de estacas é o ambiente de propagação. Segundo Pasqual et al. (2001), a umidade é um dos fatores externo extremamente fundamental para ocorrer enraizamento das estacas. Sendo assim, o maior controle da umidade no ambiente de enraizamento pode proporcionar melhoria no índice de sobrevivência e enraizamento das estacas de figueira.

Objetivou-se com o presente trabalho observar a influência da gema apical e do AIB no enraizamento de estacas apicais de figueira em diferentes ambientes de propagação.

Foram coletadas estacas lenhosas apicais de figueira no momento da poda hibernal da cultura (agosto) da coleção de fruteiras do Pomar Didático do Depto. de Agricultura, pertencente à Universidade Federal de LavrasUFLA, Lavras-MG.

As estacas foram padronizadas com $20 \mathrm{~cm}$ de comprimento, sem folhas, efetuando um corte em bisel na extremidade basal da estaca. Os tratamentos constituíram-se de estacas com ou sem a gema apical, imersas ou não em solução de AIB a 2000 mg.. $L^{-1}$ por 10 segundos e dois diferentes ambientes de propagação (casa-de-vegetação, com temperatura em torno de $27 \pm 2{ }^{\circ} \mathrm{C}$ e $85 \%$ UR; telado, com sombrite a $50 \%$ de luminosidade e regas manuais diárias), perfazendo um fatorial $2 \times 2 \times 2$, totalizando oito tratamentos, sendo utilizado o delineamento inteiramente casualizado, com quatro repetições e dez estacas por unidade experimental. As estacas foram acondicionadas em recipientes plásticos $\left(10 \times 20 \mathrm{~cm}\right.$, capacidade de $\left.650 \mathrm{~cm}^{3}\right)$, preenchido com substrato terra e areia $2: 1 \mathrm{v} / \mathrm{v}$.

Passados 60 dias foram coletados os seguintes dados biométricos: porcentagem de estacas enraizadas, porcentagem de estacas brotadas, número de folhas, número de brotos, número de raízes emitidas da estaca e comprimento médio das brotações. Os dados foram submetidos à análise de variância e as médias ao teste de Scott \& Knott (1974), ao nível de 5\% de probabilidade (GOMES, 2000). As análises foram realizadas pelo programa computacional Sistema para Análise de Variância - SISVAR (FERREIRA, 2000).

De acordo com o teste F para as características analisadas, houve significância em todas as características analisadas para o ambiente de propagação, a presença da gema apical e na interação desses dois tratamentos. Houve apenas efeito da utilização do AIB para a porcentagem de estacas enraizadas (Quadro 1).

Ciênc. agrotec., Lavras, v. 30, n. 5, p. 1021-1026, set./out., 2006 
QUADRO 1 - Análise de variância das médias da porcentagem de estacas enraizadas (PEE), número de raízes emitidas da estaca (NREE), porcentagem de estacas brotadas (PEB), número de folhas (NF), número de brotos (NB) e comprimento médio das brotações $(\mathrm{CMB}, \mathrm{cm})$ de estacas apicais de figueira em função do ambiente de propagação, gema apical e AIB diferentes épocas de crescimento e tipos de mudas de caramboleira. UFLA, Lavras-MG, 2003.

\begin{tabular}{|c|c|c|c|c|c|c|c|}
\hline Causas da variação & GL & PEE & NREE & PEB & NF & NB & CMB \\
\hline & \multicolumn{7}{|c|}{$\mathrm{F}(\mathrm{QM})$} \\
\hline Ambiente (A) & 1 & $41776^{*}$ & $2384 *$ & $38116^{*}$ & $554 *$ & $12 *$ & $196^{*}$ \\
\hline Gema apical (B) & 1 & $800^{*}$ & $1314 *$ & $894 *$ & $41 *$ & 6* & $273^{*}$ \\
\hline AIB (C) & 1 & $485^{*}$ & 22 & 174 & 1 & 1 & 1 \\
\hline $\mathrm{A} \times \mathrm{B}$ & 1 & $1086^{*}$ & $202 *$ & $977 *$ & $96 *$ & 8* & $17 *$ \\
\hline $\mathrm{A} \times \mathrm{C}$ & 1 & 1 & 16 & 8 & 2 & 1 & 1 \\
\hline B x C & 1 & 4 & 19 & 2 & 1 & 1 & 1 \\
\hline$A \times B \times C$ & 1 & 124 & 84 & 158 & 5 & 1 & 3 \\
\hline Resíduo & 23 & 55 & 9 & 56 & 1 & 1 & 1 \\
\hline $\mathrm{cv}(\%)$ & - & 14,11 & 20,06 & 13,99 & 12,26 & 26,83 & 14,08 \\
\hline
\end{tabular}

ns: não-significativo.

*: significativo $(P<0,05)$

Constatou-se que para a porcentagem de estacas enraizadas, brotadas, número de raízes emitidas da estaca e comprimento médio das brotações, a presença da gema apical propiciou melhores resultados (Tabelas 1 e 2). A capacidade de uma estaca emitir raízes está em função de fatores endógenos e fatores exógenos (FACHINELLO et al., 1995). Para estes autores, a formação de raízes adventícias deve-se à interação de tais fatores, principalmente, a translocação de substâncias localizadas nas gemas, onde está o centro de produção de substâncias hormonais, que são translocados via floema para as diversas regiões da estaca. Essas substâncias controlam a divisão celular em tecidos de plantas, podendo ser limitantes ou estimulantes nos processos fisiológicos, como o enraizamento de estacas (TORREY, 1996). Já para o número de folhas e brotos, a ausência da gema apical promoveu resultados superiores somente quando as estacas foram enraizadas em casa-de-vegetação (Tabela 2). Esse fato pode estar relacionado com a quebra da dominância apical em virtude da remoção da gema apical, o que veio a promover estímulo à brotação das estacas e conseqüentemente, aumento no número de folhas.

Com relação ao ambiente de propagação, ficou evidente que estacas no ambiente da casa-de-vegetação apresentaram os melhores resultados, havendo superioridade em relação às estacas no ambiente do telado para todas as variáveis analisadas, a exceção para o número de brotos em estacas com gema (Tabelas 1 e 2).
Esses resultados estão relacionados ao maior controle da umidade e temperatura da casa-de-vegetação. Pio et al. (2003), verificaram que estacas apicais de figueira enraizadas em casa-de-vegetação propiciam melhores resultados, em comparação as estacas enraizadas em telado e a pleno sol.

Andersen (1986) considera que a temperatura e a água são os fatores externos que merecem especial atenção na propagação de plantas por estaquia. A necessidade de água para as estacas enraizarem se baseia no fato de que logo depois de colocadas no substrato para enraizar, ainda não possuem raízes e, portanto, não têm como absorver água suficiente para compensar a transpiração e o crescimento de novas brotações (JANICK, 1966).

Com relação à utilização de AIB, apenas houve influência da aplicação dessa auxina sintética para a porcentagem de estacas enraizadas (Tabela 3). Porém, o ganho conseguido com esse fitoregulador se torna inviável, uma vez que o acréscimo obtido foi de apenas $7,92 \%$. Pio et al. (2004) também conseguiram apenas o acréscimo de $12,39 \%$ de estacas apicais de figueira enraizadas com a utilização de $2000 \mathrm{mg} \cdot \mathrm{L}^{-1} \mathrm{AIB}$, em comparação a ausência do tratamento. Esse fato pode estar relacionado à concentração endógena de auxinas nas estacas já estar em níveis já favoráveis ao enraizamento, assim a aplicação exógena não promoveu ganhos altamente significativos. 
Segundo Hartmann et al. (2002), é de extrema importância a utilização correta das concentrações de fitoreguladores a serem aplicadas à base das estacas, sendo que a concentração ideal varia com a espécie em que se está trabalhando. Para muitas espécies, têm-se observado que o enraizamento só é possível quando as estacas são imersas em fitoreguladores (ROSA, 1993), porém, existem casos em que a aplicação dessas substâncias podem inibir o enraizamento (GRZYB, 1975; PHIPPS et al., 1977).

Assim, pode-se concluir que o ambiente de casa-devegetação apresentou melhores condições para o enraizamento e desenvolvimento de estacas apicais de figueira; a presença da gema apical favorece o enraizamento das estacas; não houve efeito do fitoregulador para os parâmetros analisados, em geral.

TABELA 1 - Porcentagem de estacas enraizadas (PEE), número de raízes emitidas da estaca (NREE) e porcentagem de estacas brotadas (PEB) de estacas apicais de figueira em ambientes com e sem presença da gema apical. UFLA, LavrasMG, 2003.

\begin{tabular}{|c|c|c|c|c|c|c|}
\hline \multirow{3}{*}{ Ambiente } & \multicolumn{6}{|c|}{ Variável analisada* } \\
\hline & \multicolumn{2}{|c|}{ PEE } & \multicolumn{2}{|c|}{ NREE } & \multicolumn{2}{|r|}{ PEB } \\
\hline & Com & Sem & Com & Sem & Com & Sem \\
\hline Telado & $25,00 \mathrm{Ab}$ & $2,85 \quad \mathrm{Bb}$ & $11,00 \mathrm{Ab}$ & $0,71 \mathrm{Bb}$ & $27,50 \mathrm{Ab}$ & $5,71 \quad \mathrm{Bb}$ \\
\hline $\begin{array}{l}\text { Casa veg. } \\
\mathrm{cv}(\%)\end{array}$ & $90,00 \mathrm{Aa}$ & $\begin{array}{l}76,25 \mathrm{Ba} \\
11\end{array}$ & 32,12 Aa & $\begin{array}{l}15,37 \mathrm{Ba} \\
06\end{array}$ & 90,00 Aa & $\begin{array}{l}75,00 \mathrm{Ba} \\
13,99\end{array}$ \\
\hline
\end{tabular}

* Médias seguidas pela mesma letra maiúscula na linha e mesma letra minúscula na coluna, não diferem entre si pelo teste Scott-Knott a 5\% de probabilidade.

TABELA 2 - Número de folhas (NF), número de brotos (NB) e comprimento médio das brotações (CMB, $\mathrm{cm})$ de estacas apicais de figueira em ambientes com e sem presença da gema apical. UFLA, Lavras-MG, 2003.

\begin{tabular}{|c|c|c|c|c|c|c|}
\hline \multirow{3}{*}{ Ambiente } & \multicolumn{6}{|c|}{ Variável analisada* } \\
\hline & \multicolumn{2}{|r|}{$\mathbf{N F}$} & \multicolumn{2}{|r|}{ NB } & \multicolumn{2}{|r|}{ CMB } \\
\hline & Com & Sem & Com & Sem & Com & Sem \\
\hline Telado & $3,50 \mathrm{Ab}$ & $2,71 \quad \mathrm{Ab}$ & $1,07 \mathrm{Aa}$ & $0,85 \mathrm{Ab}$ & $8,00 \quad \mathrm{Ab}$ & $1,42 \mathrm{Bb}$ \\
\hline $\begin{array}{l}\text { Casa veg. } \\
\text { cv }(\%)\end{array}$ & $8,32 \mathrm{Ba}$ & $\begin{array}{l}13,96 \text { Aa } \\
12,26\end{array}$ & $1,28 \mathrm{Ba}$ & $\begin{array}{l}3,17 \text { Aa } \\
26,83\end{array}$ & $12,81 \mathrm{Aa}$ & $\begin{array}{l}7,12 \mathrm{Ba} \\
14,08\end{array}$ \\
\hline
\end{tabular}

* Médias seguidas pela mesma letra em maiúsculo na linha e mesma letra em minúsculo na coluna, não diferem entre si pelo teste Scott-Knott a 5\% de probabilidade.

TABELA 3 - Porcentagem de estacas enraizadas (PEE), número de raízes emitidas da estaca (NREE), porcentagem de estacas brotadas (PEB), número de folhas $(\mathrm{NF})$, número de brotos $(\mathrm{NB})$ e comprimento médio das brotações $(\mathrm{CMB}, \mathrm{cm})$ de estacas apicais de figueira com e sem o uso de AIB. UFLA, Lavras-MG, 2003.

\begin{tabular}{lllllll}
\hline & \multicolumn{8}{c}{ Variável analisada* } \\
\cline { 2 - 8 } AIB & PEE & NREE & PEB & NF & NB & CMB \\
\hline 0 & $48,75 \mathrm{~b}$ & 14,43 a & 51,25 a & 7,21 a & 1,77 a & 7,53 a \\
$2000 \mathrm{mg} . \mathrm{L}^{-1}$ & $56,67 \mathrm{a}$ & $16,13 \mathrm{a}$ & $56,00 \mathrm{a}$ & $6,84 \mathrm{a}$ & $1,46 \mathrm{a}$ & $7,54 \mathrm{a}$ \\
cv $(\%)$ & 14,11 & 20,06 & 13,99 & 12,26 & 26,83 & 14,08 \\
\hline
\end{tabular}

* Médias seguidas da mesma letra na coluna, não diferem significamente entre si pelo teste Scott-Knott ao nível de 5\% de probabilidade.

Ciênc. agrotec., Lavras, v. 30, n. 5, p. 1021-1026, set./out., 2006 


\section{REFERÊNCIAS BIBLIOGRÁFICAS}

ALVARENGA, A. A. Substâncias de crescimento e regulação do desenvolvimento vegetal. Lavras: UFLA, 1990. $59 \mathrm{p}$.

ANDERSEN, A. S. Enviomental influences on adventitious rooting in cuttings of now-woody species. In: JACKSON, M. B. (Ed.). New root formation in plants and cuttings. London: M. Nijhoff, 1986. p. 223-254.

ANTUNES, L. E. C.; CHALFUN, N. N. J.; RAMOS, J. D.; PASQUAL, M.; VEIGA, R. D. Influência de diferentes períodos de estratificação, concentrações de ácido indolbutírico e substratos no enraizamento de estacas de figueira. Ciência e Agrotecnologia, Lavras, v. 20, n. 3, p. 307-314, jul./set. 1996.

CHALFUN, N. N. J.; HOFFMANN, A. Propagação da figueira. Informe Agropecuário, Belo Horizonte, v. 18, n. 188, p. 9-13, 1997.

CHALFUN, N. N. J.; PASQUAL, M.; HOFFMANN, A. Fruticultura comercial: frutíferas de clima temperado. Lavras: UFLA/FAEPE, 1997. 304 p.

COELHO, G. V. de A.; CHALFUN, N. N. J.; MIRANDA, C. S. de; VEIGA, R. D.; GONÇALVES, F. C. Efeito da época de poda da cienamida hidrogenada e da cobertura de solo na produção antecipada de fìgo verde da cultivar roxo de valinho. In: CONGRESSO BRASILEIRO DE FRUTICULTURA, 17., 2002, Belém. Anais... Belém: SBF, 2002. CD-ROM.

FACHINELLO, J. C.; HOFFMANN, A.; NACHTIGAL, J. C.; KERSTEN, E.; FORTES, G. R. de L. Propagação de plantas frutíferas de clima temperado. 2. ed. Pelotas: UFPel, $1995.178 \mathrm{p}$.

FERREIRA, D. F. Análise estatística por meio do SISVAR (Sistema para Análise de Variância) para Windows versão 4.0. In: REUNIÃO ANUAL DA REGIÃO BRASILEIRA DA SOCIEDADE INTERNACIONAL DE BIOMETRIA, 45., 2000, São Carlos. Anais... São Carlos: UFSCar, 2000. p. 255258.

GOMES, F. P. Curso de estatística experimental. 14. ed. Piracicaba: USP/ESALQ, 2000. 477 p.
GONÇALVES, F. C. Formas de acondicionamento a frio de estacas e mudas de figueira (Ficus carica L.). 2002. 84 p. Dissertação (Mestrado em Agronomia) - Universidade Federal de Lavras, Lavras, 2002.

GRZYB, Z. S. The effect of growth substances on the rooting of softwood cuttings of plum rootstock. Fruit Science Reports, Skierniewice, v. 2, n. 4, p. 33-44, 1975.

HARTMANN, H. T.; KESTER, D. E.; DAVIES JUNIOR, F. T.; GENEVE, R. L. Plant propagation: principles and practices. 7. ed. New Jersey: Prentice Hall, 2002. 880 p.

HINOJOSA, G. F. Auxinas. In: CID, L. P. B. (Ed.). Introdução aos hormônios vegetais. Brasília, DF: Embrapa, 2000. p. 1554.

HOFFMANN, A.; CHALFUN, N. N. J.; ANTUNES, L. E. C.; RAMOS, J. D.; PASQUAL, M.; SILVA, C. R. de R. e. Fruticultura comercial: propagação de plantas frutíferas. Lavras: UFLA/FAEPE, 1996. 319 p.

INSTITUTO DE ESTATÍSTICAS DA AGRICULTURA. Anuário de informações estatísticas da agricultura. São Paulo, 2002. 265 p.

JANICK, J. A. A ciência da horticultura. Rio de Janeiro: F. Bastos, 1966. $485 \mathrm{p}$.

PASQUAL, M.; CHALFUN, N. N. J.; RAMOS, J. D.; VALE, M. R. do; SILVA, C. R. de R. e. Fruticultura comercial: propagação de plantas frutíferas. Lavras: UFLA/FAEPE, 2001. $137 \mathrm{p}$.

PENTEADO, S. R. O cultivo da figueira no Brasil e no mundo. In: CORRÊA, L. S. de; BOLIANI, A. C. (Eds.). Cultura da figueira: do plantio à comercialização. Ilha Solteira: FAPESP, 1999. p. 1-16.

PHIPPS, H. M.; BELTON, D. A.; NETZER, D. A. Propagating of some Populus clones for tree plantations. The Plant Propagator, [S.1.], v. 23, p. 8-11, 1977.

PIO, R. Ácido indolbutírico e sacarose no enraizamento de estacas apicais e desenvolvimento inicial da figueira (Ficus carica L.). 2002. 109 p. Dissertação (Mestrado em Agronomia) - Universidade Federal de Lavras, Lavras, 2002. 
PIO, R.; GONTIJO, T. C. A.; CARRIJO, E. P.; VISIOLI, E. L.; TOMASETTO, F.; CHALFUN, N. N. J.; RAMOS, J. D. Enraizamento de estacas apicais de figueira em diferentes acondicionamentos e ambientes distintos. Revista Brasileira de Agrociência, Pelotas, v. 9, n. 4, p. 357-360, out./dez. 2003.

PIO, R.; RAMOS, J. D.; CHALFUN, N. N. J.; COELHO, J. H. C.; GONTIJO, T. C. A.; CARRIJO, E. P.; VILLA, F. Enraizamento adventício de estacas apicais de figueira e desenvolvimento inicial das plantas no campo. Revista Ciência e Agrotecnologia, Lavras, v. 28, n. 1, p. 215-221, jan./fev. 2004.

ROSA, L. S. Influência de diferentes concentrações de ácido indol-3-butírico e do tamanho da estaca na formação de raízes adventícias em Carapa guianensis Aubl. In: CONGRESSO FLORESTAL PANAMERICANO, 1.; CONGRESSO FLORESTAL BRASILEIRO, 7., 1993, Curitiba. Anais... Curitiba: SBS/SBEF, 1993. v. 2, p. 432-434.

SCOTT, A. J.; KNOTT, M. A cluster analysis method for grouping means in the analysis of variance. Biometrics, Washington, v. 30, p. 507-512, Sept. 1974.

SILVA, C. R. de R. e. Propagação. Informe Agropecuário, Belo Horizonte, v. 9, n. 102, p. 30, 1983.

TORREY, J. G. Endogenous and exogenous influences on the regulation of lateral root formation. In: JACKSON, M. B. (Ed.). New root formation in plants and cuttings. Dordrecht: M. Nijhoff, 1996. p. 31-66.

Ciênc. agrotec., Lavras, v. 30, n. 5, p. 1021-1026, set./out., 2006 